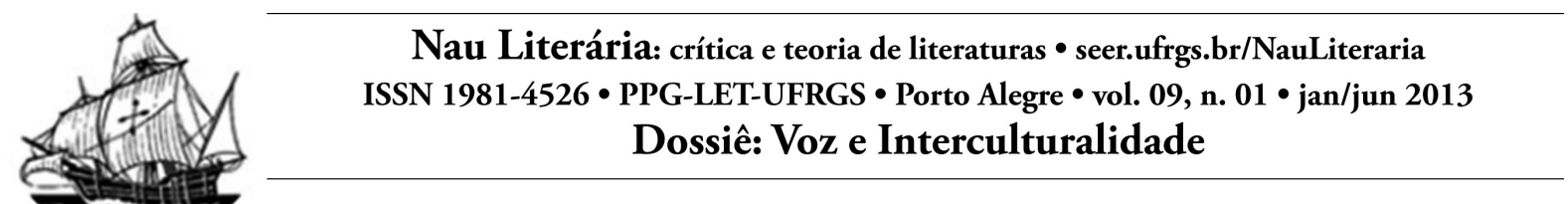

\title{
POESIA FEMININA SUBALTERNA NEGRA: UMA VOZ DE RESISTÊNCIA.
}

\author{
Taise Campos dos Santos Pinheiro de Souza ${ }^{1}$
}

\begin{abstract}
Resumo: Em todo um processo histórico de opressão e exclusão da mulher por nossa sociedade patriarcal, pautada e normatizada pelo discurso masculino e branco, vimos as mulheres, especialmente as negras, ficarem relegadas ao silenciamento. Uma maior repressão às vozes de mulheres negras e consequentemente de suas produções se deve ao fato destas serem marcadas pelo preconceito em duas instâncias: a de gênero e a de raça, e por vezes a de classe. Diante dessa conjuntura, o seguinte trabalho busca refletir e discutir sobre poesias das escritoras negras Alzira Rufino e Conceição Evaristo que falam, debatem, tencionam sobre diversas questões socioculturais em torno da mulher negra e todo esse processo de exclusão e silenciamento, por meio desse mecanismo. Com isso buscamos mostrar como as vozes poéticas dessas mulheres tornam-se ferramentas que podem desconstruir estereótipos, "balançar" com estruturas socioculturais historicamente fixadas, e com a potencialidade de suas poesias podem lutar contra a opressão, exclusão e a negação de suas alteridades, ecoando suas vozes como forma de protesto, de resistência, em busca de serem ouvidas e de intervirem contra uma exclusão patriarcal construída historicamente em torno da mulher, principalmente a negra. Para embasar teoricamente esse trabalho nos pautaremos em autores (as) como Miriam Alves (2010), Vera Soares (2000), Ana Rita Silva (2010), Michel Foucault (2000), Roland Walter (1999), Rita Schmidt (1995), entre outros (as). Sendo assim a poesia constituise como forma de conscientização política e social, mostrando que estas mulheres negras, lutam, denunciam e buscam transformar um sistema hegemônico dominante que de vários modos as subalternizam, desestabilizando assim um conceito tradicional de subalternidade e dando um novo enfoque à literatura. É preciso, então, atentar para as vozes que foram e ainda por vezes são silenciadas, "abafadas" por discursos hegemônicos, fixos, enrijecidos, perpassálas, trabalhando por meio de uma construção cultural em que essas vozes femininas negras sejam reconhecidas em sua alteridade e autonomia.
\end{abstract}

Palavras-chave: vozes poéticas; escritoras negras; subalternidade; resistência.

Abstract: Throughout a historical process of oppression and exclusion of women by our patriarchal society, guided and standardized by the male discourse and white, we have seen the women, especially the black, staying relegated to the muting. A greater repression to voices of black women and consequently of their productions is due the fact of these be marked by prejudice in two instances: the of gender and race, and, sometimes, of class. Given this conjuncture, the following work to seeks to reflect and discuss poetry of black women writers Alzira Rufino and Conceição Evaristo who speak, debating, intend about various

\footnotetext{
${ }^{1}$ Mestranda do Programa de Pós-graduação em Crítica Cultural - UNEB/ Campus II. Pesquisadora/FAPESB. Email: tai_campos@hotmail.com.
} 
socio-cultural issues around the black woman and this whole process of exclusion and muting, through that mechanism. With that we seek to show how the poetic voices of these women become tools that can deconstruct stereotypes, "swing" with sociocultural structures historically fixed, and with the potentiality of his poetry they can fight oppression, exclusion and denial of its alterities, echoing their voices as a protest, resistance, in search to be heard orally and to intervene against an exclusion patriarchal historically constructed around the woman, mostly black. To theoretical basis this work roleing in authors as Miriam Alves (2010), Vera Soares (2000), Ana Rita Silva (2010), Michel Foucault (2000), Roland Walter (1999), Rita Schmidt (1995), among others. So the poetry is constituted as a form of political and social raising awareness, showing that these black women, are fighting, denouncing and are seeking transform a dominant hegemonic system that in various ways the subalternizam, thus destabilizes traditional concept of subalternity and giving a new approach to literature., Is precise then pay attention to the voices that were and still are sometimes silenced, "muffled" by hegemonic discourses, fixed, hardened, pervade, effectively working through a cultural construction that these black feminine voices are recognized in its otherness and autonomy.

Key-words: poetic voices; black women writers; subalternity; resistance.

Diante de uma conjuntura histórica construída tradicionalmente pelo viés masculino e hegemônico, por vezes a mulher ainda não tem sua voz reconhecida e visibilizada, sendo esta, na maioria das vezes, abafada por outros discursos pautados e normatizados sob a ótica patriarcal. Nesse contexto de opressão, a escrita das mulheres, foi por muito tempo ignorada e socialmente não aceita, sendo ainda, as mulheres negras e suas escritas marcadas pelo preconceito em duas instâncias: a de gênero e a de raça.

Sendo assim, a quebra de um silenciamento imposto à voz feminina, especialmente a negra, constitui um difícil processo de luta, de enfrentamento, de inclusão sociocultural e política, que vem, paulatinamente, se desenvolvendo ao longo do tempo.

Diante do exposto, é preciso, então, atentar para as vozes que foram e ainda por vezes são silenciadas, "abafadas" por discursos hegemônicos, fixos, enrijecidos, perpassá-las, trabalhando por meio de uma construção cultural em que essas vozes femininas negras sejam reconhecidas em sua alteridade e autonomia.

Desse modo, torna-se necessário cultivar a voz feminina negra, visibilizá-la, elucidando as potencialidades de seus discursos em meio a outros já perpassados e instituídos. Portanto, podemos perceber que: "Ser mulher e escritora no Brasil é romper com o silêncio, a "não-fala" e transpor os espaços que definem procederes e funções preestabelecidas". (ALVES, 2010-2011, p.183) 
Essa questão do poder de fala nos faz pensar nos jogos circunscritos de poder presentes na interdição, depreciação de algumas vozes, discursos e em contrapartida na vontade de verdade que há em outros discursos, (FOUCAULT, 2000) e nesse entremeio refletir sobre o processo histórico de silenciamento, subalternização de mulheres/escritoras negras. Para tanto, é preciso refletir sobre essa questão da subalternidade, e nos perguntar, quem é esse ser subalterno, ele fala ou não, ele age ou não? No texto Estudos subalternos (1997) do grupo latino-americano de estudos subalternos, Guha, um dos membros do referido grupo, opera uma desconstrução de uma noção passiva do sujeito subalterno, que naturalmente é perpassada, mostrando que o sujeito subalterno, apesar das forças que incidem contra ele, está em ação e produz efeitos sociais visíveis, seja na escrita, na literatura, na educação etc., ou seja, ele reconhece um papel ativo do subalterno. Deste modo, podemos afirmar que:

[...] o prefixo "sub" de sub-alternidade não implica "um estar abaixo de", "um obedecer a alguém", mas uma espécie de devir revolucionário (num indivíduo, tribos, nações, culturas, instituições, etc.) capaz de irromper-se e jogar com as alternâncias de poder. (SANTOS, 2008, p. 5).

Sendo assim, podemos dizer que o sujeito subalterno se move a partir de micro revoluções, através de sua fala, sim, através de suas ações, no caso de escritoras negras subalternas, como Alzira Rufino ${ }^{2}$ e Conceição Evaristo ${ }^{3}$ por meio da literatura, de suas poesias que se constituem instrumentos de questionamento contra um sistema excludente, ao mesmo tempo em que dar visibilidade à mulher negra. Através dessa escrita que é socialmente, culturalmente e politicamente engajada, essas autoras contribuem com a ressignificação do conceito de subalternidade, uma vez que se mostram em pleno devir, ação, apesar da subalternização que incide sobre elas, mostrando que apesar de serem subalternizadas como tantas outras mulheres negras, elas buscam lutar, falar, escrever, ecoar suas vozes como gesto de luta e resistência.

\footnotetext{
${ }^{2}$ A escritora Alzira dos Santos Rufino nasceu em Santos - SP, em 1949. Começou os estudos na área de saúde, graduando-se em enfermagem. Notória ativista do movimento negro e especialmente do Movimento negro feminino, fundou o "Coletivo de Mulheres Negras da Baixada Santista", em 1986 e a "Casa de Cultura da Mulher Negra", em 1990, Para mais detalhes consultar www.letras.ufmg.br/literafro.

${ }^{3}$ A escritora Conceição Evaristo de Brito nasceu em Belo Horizonte - MG, 1946. Graduou-se em Letras pela UFRJ. É Mestre em Literatura Brasileira pela PUC do Rio e Doutora em Literatura Comparada pela Universidade Federal Fluminense. Participante e ativista dos movimentos em favor da cultura afro-brasileira e negra. Para mais detalhes consultar www.letras.ufmg.br/literafro.
} 
Assim, a partir de um novo olhar sobre o conceito de subalternidade, percebemos que, apesar das diversas exclusões que recaem sobre o sujeito subalternizado, este é crítico e participante em seu contexto social, assim como as escritoras subalternas negras aqui tratadas. Ou seja, apesar da invisibilidade construída historicamente e forçosamente sobre estas, elas falam, produzem, escrevem, apesar de sabermos que: "Escrever da perspectiva de uma mulher sempre foi um desafio, tanto para se encaixar como para resistir em uma arena feita principalmente por e para homens" (CALIZ-MONTORA, 1999, p. 79). Esse desafio é maior ainda, quando a escrita é realizada por mulheres negras, a partir de suas vivências e perspectivas. Diante disso, as formas discursivas expressas nas poesias de Alzira Rufino e Conceição Evaristo configuram-se, então, como uma prática de resistência e de transgressão, atuando contra a subalternização imposta a estas.

É notável que a participação da mulher negra no campo literário deu um novo enfoque à sua própria imagem, promovendo, gradativamente, a ruptura de sua subalternização e do seu silenciamento. Essa luta de mulheres negras pela escuta de suas vozes é antiga e permanece em nossos tempos, abaixo podemos ver um exemplo dessa escrita no poema Vozes Mulheres (1990) de Conceição Evaristo:

A voz de minha bisavó ecoou criança nos porões do navio.

Ecoou lamentos de uma infância perdida.

A voz de minha avó ecoou obediência aos brancos-donos de tudo.

A voz de minha mãe ecoou baixinho revolta no fundo das cozinhas alheias debaixo das trouxas roupagens sujas dos brancos pelo caminho empoeirado rumo à favela.

A minha voz ainda ecoa versos perplexos com rimas de sangue 
fome.

A voz de minha filha

recolhe todas as nossas vozes

recolhe em si

as vozes mudas caladas

engasgadas nas gargantas.

A voz de minha filha

recolhe em si

a fala e o ato.

O ontem - o hoje - o agora.

Na voz de minha filha

se fará ouvir a ressonância

o eco da vida-liberdade.

O poema Vozes mulheres, de Conceição Evaristo é uma amostra de como a mulher subalternizada, por um sistema de exclusão contínuo e de longo tempo, utiliza a escrita para fazer lembrar esse processo de opressão, sufocamento e emudecimento das vozes das mulheres, especialmente as negras. A voz poética do texto, através do movimento memorialístico e histórico, que relembra os processos de exclusões, opressões, silenciamentos passados de gerações em gerações por mulheres negras, nos faz refletir o quanto somos subalternizadas a cada momento, a cada época e o quanto é necessário lutar, falar, escrever, pelas mulheres de hoje e por aquelas que foram alvo desse sistema de subalternização. Afirma como o ato de falar, de poder exprimir sua voz é uma verdadeira forma de libertação, de emancipação por parte da mulher por tanto tempo e de diversas formas subjugadas. Sobre isso a autora Zilda Freitas (2002, p.122) nos diz que: “As mulheres, atualmente, escrevem também por todas aquelas que nos séculos anteriores e mesmo hoje em dia, em culturas mais restritivas, são silenciadas".

A escrita feita da perspectiva de mulheres negras e que tem como temática a luta e a vida das mesmas tornou-se ferramenta de transgressão dos espaços, dos limites, por muito tempo impostos às mulheres, e, com isso, um processo gradativo de conquista de autonomia e de quebra do silenciamento, permitindo, ao mesmo tempo, o empoderamento destas, especialmente por meio da literatura:

A literatura não é para as mulheres uma simples transgressão das leis que lhes proibiam ao acesso à criação artística. Foi muito mais do que isso, um território liberado, clandestino. Saída secreta da clausura da linguagem e de um pensamento masculino que as pensava e as descrevia in absentia. (FREITAS, 2002, p.119). 
Muito se tem falado do espaço que as mulheres têm conquistado no campo da literatura, com produções cada vez mais significantes e revolucionárias, que, gradativamente, têm contribuído com a transformação dos diversos contextos em que se inserem. Entretanto, é preciso lembrar que essa conquista é fruto de um longo e contínuo processo de luta e resistência, em meio à exclusão patriarcal estabelecida pelas sociedades:

Às mulheres foi negada a palavra. Mas rompendo o silêncio, ao buscar formas de expressão, a mulher encontrou nos gêneros de fronteira espaço necessário para conquistar a voz e expressar sua subjetividade. Neste lugar, no que está do outro lado, a narradora feminina escreveu cartas, diários, histórias do cotidiano banal. Ao contrário do homem, a mulher não tinha nada de extraordinário para contar, e ela contou, e ao contar contou-se. (REIS, 1996, p. 175).

A apropriação da escrita, por parte das mulheres, foi fundamental nesse processo de rompimento de um silêncio imposto a estas, durante longo tempo, por parte de uma sociedade patriarcal. Foi justamente através dos escritos de mulheres transgressoras que percebemos, pouco a pouco, a revelação de vozes que infundiram em nossa literatura um novo modo de ver e reconhecer a mulher, e muito mais outros sujeitos marginalizados por um cânone literário.

Isso é resultado de um longo processo de luta exercido por mulheres, como as poetisas, aqui abordadas, que souberam transgredir um sistema literário rígido, em que a negação da presença das mulheres, principalmente negras, sempre fora perpassada em suas entrelinhas. Esse movimento de transgressão e de ratificação da presença e resistência das mulheres negras é o que podemos apreciar no poema Boletim de Ocorrência, de Alzira Rufino (1988):

\author{
Mulher negra, \\ Não para \\ Por essa coisa bruta \\ Por essa discriminação morna, \\ Tua força ainda é segredo, \\ mostra tua fala nos poros \\ O grito ecoará na cidade, \\ Capinam como mato venenoso \\ a tua dignidade, $[. .$. \\ Tua negritude incomoda \\ Teu redemoinho de forças afoga \\ Não querem a tua presença \\ Riscam teu nome com ausência.
}

Mulher negra, chega 


\section{Mulher negra, seja \\ Mulher negra veja \\ Depois do temporal. \\ $[\ldots]$ \\ Transpiro a liberdade.}

Observamos nos versos de Alzira Rufino, como o eu poético expressa a força, a luta da mulher negra que diante de situações históricas e cotidianas de opressão, discriminação e invisibilização, busca mostrar sua voz, sua força, suas condições de intervir e agir em nossa sociedade de forma crítica e autônoma. A voz poética do texto além de aludir às formas de opressão para com a mulher negra, ao mesmo tempo em que afirma a força, a presença e a resistência desta, instiga a tantas outras mulheres negras submetidas aos mesmos processos de exclusão a resistirem, a não se manterem passivas, diante da discriminação, formas de abuso culturais e sociais que tentam anular sua vez, sua voz, sua ação.

A poesia, então se torna um meio crítico reflexivo de se pensar essa mulher negra, o sistema social hegemônico e excludente, e uma forma de retratar a dinâmica de atuação dessas mulheres, que mantém posturas autônomas e diferenciadas, configurando um lirismo políticosocial que:

[...] se caracteriza pela expressão lírica de uma postura crítica das poetizas ante as mazelas políticas, econômicas e sociais que captam da realidade na qual se inserem. [...] esse tipo de poesia é igualmente revelador se enfocamos a presença das mulheres na sociedade e suas reações aos sistemas de controle social. Em muitas escritoras, encontramos um imaginário atado ao passadismo, certas vezes mesmo reacionário. Em outras, isso sim, conferimos uma postura crítica que demonstra grande capacidade de repensar a realidade social, imprimindo nos textos um desejo vivo de transformação, justiça e igualdade. (RAMALHO, 2011, p. 32).

Esse pode ser considerado um trabalho poético revolucionário tanto para a literatura em geral, como para a feminina, uma vez que insere na arte da escrita outro discurso autônomo, que irrompe em uma estrutura discursiva historicamente canonizada.

Os discursos proferidos pelas escritoras Alzira Rufino e Conceição Evaristo nos levam a inferir sobre o termo subalternidade um novo sentido, uma vez que fazem da escrita poética uma forma de denúncia, revolução, contestação dos parâmetros sociais estabelecidos, uma forma de testemunho e: "o testemunho acirra a discussão dos gêneros e radicalmente abre espaço para os que foram silenciados: (...), subalternos e marginalizados." (REIS, 1996, p.175). 
É importante percebermos que a escrita produzida por mulheres subalternizadas ressignifica a nossa literatura por trazer, para esta, uma nova imagem e concepção do "ser" mulher, diferentemente de algumas imagens e conceitos estereotipados sobre as mulheres, produzidos por muitos textos de autoria masculina. É de suma importância sabermos o quanto a escrita feminina contribui para a emancipação da mulher, é muito significante reconhecer que:

Nunca se falou tanto, nunca se escreveu tanto sobre mulher e literatura [...] fato inusitado no contexto de uma história literária e tradição crítica de mais de dois mil anos, história essa construída e constituída por um corpus de textos canonizados e escritos no registro do masculino. (SCHMIDT, 1995, p.182).

O reconhecimento da escrita feminina negra, da significância desta para a nossa literatura vem justamente quebrar com uma exclusão literária sofrida pelas mulheres em nosso processo histórico, nos fazendo constatar que: "Escrever tem sido um meio eficaz de provocar mudanças, e as mulheres têm feito uso dessa ferramenta apesar das restrições a que têm estado sujeitas." (CALIZ-MONTORA, 1999, p. 79).

Então, dentro desse processo, pensamos que a literatura:

[...] Prática artística e discurso altamente prestigiado, é perpassada por uma série de valores culturais, dialogando com as relações de poder presentes na sociedade. São criações artísticas que podem ser transgressoras ou reprodutoras de estereótipos (...) (LEAL, 2011, p. 217).

As poesias de Alzira Rufino e Conceição Evaristo é um exemplo dessa atuação transgressora no meio literário, pois estas, enquanto pertencentes às chamadas minorias de mulheres, marginalizadas, subjugadas e excluídas por um sistema social dominante, buscaram, através da literatura, revolucionar esses sistemas estabelecidos, “jogar" com as relações de poder existentes na sociedade, fazendo ecoar suas vozes, através da escrita, da poesia. Vozes que se tornam um ato político de luta e resistência, comprovando como a literatura, a partir de um novo enfoque desconstrutor e não reprodutor de estereótipos e preconceitos pode ser uma ferramenta na luta social de mulheres excluídas, subalternizadas, confirmando que, através da escrita, podemos buscar transformar nosso contexto histórico, cultural e social, podemos transgredir com os sistemas sociais injustamente estabelecidos, podemos, enfim, ressignificar a nós e ao mundo, fazer a diferença: “[...] a escritura, suscetível de uma prática domiciliar (assim como a pintura), é uma das primeiras conquistas femininas e também uma das que provocaram mais forte resistência”. (PERROT apud GONÇALVES, 2006, p. 24). 
Os poemas das escritoras Alzira Rufino e Conceição Evaristo trazem à tona a imagem emancipada da mulher, que se insere em seu contexto social, como sujeito crítico e autônomo, como pessoa. Nessa perspectiva Fonsêca (2011, p. 202) nos diz que: “(..) Nos textos de autoria feminina geralmente a mulher é representada como elemento partícipe do contexto social, um indivíduo capaz de construir uma vida baseada em princípios particulares. Ou seja, a mulher é representada como sujeito." Além disso: “A escrita de autoria feminina é marcada por uma alteridade que lhe é peculiar, pois, por meio de uma linguagem própria, diferenciada, cheia de símbolos, faz emergir sujeitos femininos descentralizados, em relação aos padrões dominantes.” (MOURA, ZOLIN 2009, p.41). É necessário ratificar a importância da mulher no campo literário, já que:

Falar sobre a instituição "literatura" e a presença da mulher no espaço dos discursos e saberes é, pois, um ato político, pois remete às relações de poder inscritos nas práticas sociais e discursivas de uma cultura que se imaginou e se construiu a partir do ponto de vista normativo masculino, projetando seu outro na imagem negativa do feminino. (SCHMIDT, 1995, p. 135).

A mulher insere em sua escrita as suas próprias vivências. Seja de forma direta ou indireta suas marcas experienciais influenciam naquilo que será dito, por isso a escrita feminina negra torna-se mais relevante para se conhecer e entender a própria mulher negra, já que suas escritas são permeadas por suas subjetividades, é o que podemos conferir no poema Resgate, de Alzira Rufino (1995):
Sou negra ponto final
Devolva-me a identidade
Rasgue minha certidão
Sou negra sem reticências
Sem vírgulas e sem ausências
Não quero mais meio-termo
Sou negra balacobaco
Sou negra noite cansaço
Sou negra ponto final.

Podemos perceber como a escritora por meio da voz poética de Resgate lança sobre si enquanto mulher negra um novo olhar, uma afirmação identitária que vai contra outras representações ou formas estereotipadas de conhecimento da mulher negra. É um poema em que a subjetividade, a vivência e experiência de quem diz e escreve estão entrelaçadas com o que expressa a voz poética do texto, entrelaçamento que é potencialmente político, em um sentido crítico de pensar a existência e importância da mulher negra. Assim, a voz poética 
irrompe-se como afirmação da presença e alteridade da mulher negra, e dessa forma a representa e a (re) significa.

É perceptível a diferença que a escrita das mulheres negras causou na literatura, aqui, especialmente, ratificamos esse impacto, através de poemas das autoras Alzira Rufino e Conceição Evaristo que são de grande relevância para a consolidação da autonomia e valorização da mulher negra. A literatura construída por essas mulheres é uma de suas melhores formas de resistência, pois atua na quebra do emudecimento de suas vozes, evoca a valorização do ser feminino, especialmente marcado pela negritude e revoluciona o macro sistema literário e social, a partir de suas ações micropolíticas. A atuação dessas escritoras, por meio da escrita literária, poética dá a ideia de deslocamento da dita escrita convencional e: "Este deslocamento é esteticamente recriado na e através da literatura feminina das minorias via uma retórica contra-hegemônica (...)” (ANZALDUA apud WALTER, 1999, p.177).

Constatamos então que a literatura é um campo de atuação de grande potencial para as escritoras Alzira Rufino e Conceição Evaristo, e a poesia, enquanto discurso literário, que é socialmente e culturalmente crítico, a partir da perspectiva dessas escritoras, constitui-se como uma eficaz ferramenta, pois por meio de suas vozes poéticas, essas escritoras trabalharam com a sua significância e existência de milhares de mulheres, especialmente negras, que por muito tempo foram oprimidas por nossa sociedade. É uma escrita contextualizada e que não deixa esquecidas as mazelas sofridas pelas mulheres, rememora, realoca as situações de exploração das mulheres, como podemos constatar no poema $A$ Noite que Não Adormece nos Olhos das Mulheres de Conceição Evaristo (2008):

A noite não adormece
nos olhos das mulheres,
a lua fêmea, semelhante nossa,
em vigília atenta vigia
a nossa memória.
A noite não adormece
nos olhos das mulheres,
há mais olhos que sono
onde lágrimas suspensas
virgulam o lapso
de nossas molhadas lembranças.

A noite não adormece 
nos olhos das mulheres, vaginas abertas

retêm e expulsam a vida

donde Ainás, Nzingas, Ngambeles

e outras meninas luas

afastam delas e de nós

os nossos cálices de lágrimas.

A noite não adormecerá

Jamais nos olhos das fêmeas, pois do nosso sangue-mulher

de nosso líquido lembradiço

em cada gota que jorra

um fio invisível e tônico

pacientemente cose a rede

de nossa milenar resistência.

Observamos no texto acima como a voz poética enfatiza o movimento de lembrar e resistir, trazendo à cena, por meio de uma linguagem ficcional a própria realidade de opressão, mas também de luta, de afirmação da vida experimentada por mulheres negras ao longo de muito tempo. Essa resistência se constrói época a época, contexto a contexto, mas não deixa de existir, mesmo que seja por muitas vezes negada, invisibilizada a presença da mulher e sua força. Assim, evidencia-se como a expressão poética é uma forte ferramenta de reflexão de diversos aspectos da vida da mulher negra, suas demandas, questionamentos e ações.

Sendo assim, a escrita constitui-se como forma de consciência subjetiva, política e social, ratificando que a produção textual feminina negra apresenta: "um potencial de transformação que nem de longe deve ser subestimado." (Gonçalves, 2006, p.23).

Portanto, por meio do cultivo de vozes femininas negras, como as de Alzira Rufino e Conceição Evaristo, é que podemos empreender uma literatura legitimamente "revolucionária", em que as diferenças sejam reconhecidas e aceitas em suas autonomias e alteridades. É assim, que podemos pouco a pouco retirar da esfera da invisibilidade as mulheres negras, sua força, voz, resistência e suas potencialidades.

\section{REFERÊNCIAS}


ALVES, Miriam. A literatura negra feminina no Brasil - pensando a existência. Revista da ABPN, v. 1, n. 3 - nov. 2010 - fev. 2011, p. 181-189.

CALIZ-MONTORA, Carmen. Feminismo Radical e o lugar da nova mestiça. In: CAPELATO, Maria Helena Rolim; HOLANDA, Heloísa Buarque de. (Orgs.) Relações de gênero e diversidade culturais nas Américas. São Paulo: Edusp, 1999.

EVARISTO, Conceição. (1990). Vozes- Mulheres. In: (Org.) Ed. dos Autores. Cadernos Negros 13. São Paulo: Quilombhoje.

EVARISTO, Conceição. Poemas da recordação e outros movimentos. Belo Horizonte: Nandyala,(coleção Vozes da Diáspora Negra, Volume 1), 2008.

FONSÊCA, Joseana Souza da. O espaço subalterno em Nélida Piñon. In: (Orgs.) GOMES, Carlos Magno; ZOLIN, Lúcia Osana. Deslocamentos da escritora brasileira. Maringá: Eduem, 2011.

FOUCAULT, Michel. A ordem do discurso. São Paulo: Loyola, 2000.

FREITAS, Zilda de Oliveira. A literatura de autoria feminina. In: (Orgs.) FERREIRA, Sílvia Lúcia; NASCIMENTO, Enilma Rosendo do. Imagens da mulher da cultura contemporânea. Salvador: NEIM/UFBA,2002.

GONÇALVES, Andréa Lisly. História e Gênero. Belo Horizonte: Autêntica, 2006.

GUHA, Ranajit (Ed.). A Subaltern Studies. 1986-1995. Minneapolis: University of Minnesota Press, 1997.

LEAL, Virgínia Maria Vasconcelos. Corpos Gêneros e Identidades nos Romances de Elvira Vigna. In: GOMES, Carlos Magno; ZOLIN, Lúcia Osana. (Orgs.). Deslocamentos da escritora brasileira. Maringá: Eduem, 2011.

MOURA, Andiara Maximiano de; ZOLIN, Lúcia Osana. Construção de personagens femininas em Vozes num divertimento, de Luci Collin. SINAGEL-SIMPÓSIO NACIONAL DE PESQUISA EM ESTUDOS LITERÁRIOS. Maringá: Departamento de Letras. ed, 2009. p. 39-49.

RAMALHO, Christina. As faces líricas da escritora brasileira. In: In: (Orgs.) GOMES, Carlos Magno; ZOLIN, Lúcia Osana. Deslocamentos da escritora brasileira. Maringá: Eduem, 2011 .

REIS, Lívia de Freitas. Autobiografia, testemunho e ficção: uma relação delicada. 1996, p.173-185.

SANTOS, Osmar Moreira dos. Subalternos Agrestes e seus Cordéis Encantados. In: XI Congresso Internacional da ABRALIC, 2008, São Paulo. Tessituras, Interações, Convergências, 2008. 
SCHMIDT, Rita Terezinha. Repensando a cultura, a literatura e o espaço da autoria feminina. In: Gênero e Literatura na América Latina. Org. Marcia Navarro. Porto Alegre, EDURGS, 1995.

SILVA. Ana Rita Santiago da. Literatura de autoria feminina negra: (des)silenciamentos e ressignificações. Revista de Letras: Vitória da conquista: v.2, n.1; p.20-37, jan.-jun. 2010.

SOARES, Vera. O verso e reverso da construção da cidadania feminina, branca e negra no Brasil. In: GUIMARÃES, Antônio Sérgio Alfredo; HUNTLEY, Lynn. (Orgs.) Tirando a máscara: Ensaios sobre o racismo no Brasil. São Paulo: Paz e Terra: 2000.

WALTER, Roland. Escritoras chicanas, afro-americanas e indígenas nos EUA: narrativa, mundo e consciência das margens. In. REIS, Lívia Freitas de; VIANNA, Lúcia Helena; PORTO, Maria Bernadette. (Orgs.) Mulher e Literatura. VII Seminário Nacional. Niterói, RJ: EDUFF, 1999.

Outras fontes:

Rufino, Alzira. Poemas. $\quad$ Disponível em: http://www.casadeculturadamulhernegra.org.br/alzira poemas.htm acesso em 17 jun. 2012 e 12 abr. 2013.

Literafro. Biografia e Literatura de autores afro-brasileiros. Disponível em: www.letras.ufmg.br/literafro acessado em 08 jan. de 2012 e 17 jul. 2013. 